\title{
El rastreo de Diabetes Tipo 2 en adultos de alto riesgo no disminuiria la mortalidad
}

\author{
Screening for type 2 diabetes in high risk adults would not decrease mortality
}

Simmons RK. y col. Lancet 2012;380(9855):1741-8.

\section{Objetivos}

Comparar la mortalidad entre pacientes sometidos a rastreo de diabetes tipo 2 (DBT2) al inicio del estudio versus pacientes no rastreados.

\section{Diseño, lugar y población}

Ensayo clínico pragmático de grupos paralelos*, aleatorizado por clusters*. Se aleatorizaron por minimización* 33 centros de atención primaria en Inglaterra a: 1) rastreo + tratamiento multifactorial intensivo para los pacientes DBT2 $(n=15) ; 2)$ rastreo + tratamiento usual del paciente DBT2 $(n=13)$; grupo control de no rastreo $(n=5)$. Se incluyeron 20.184 individuos entre 40 a 69 años con alto riesgo de DBT2 basado en un score de riesgo. Se incluyeron centros de salud que puedan proveer información para calcular el score de riesgo de DBT2 de al menos 70\% de sus pacientes. Se excluyeron pacientes que cursaran embarazo, lactancia, enfermedad con pronóstico de sobrevida menor al año, enfermedad psiquiátrica que invalidara el con- sentimiento informado o que pudiese restringir la participación en el estudio así como aquellos pacientes con recomendación de participación negativa del médico tratante.

\section{Intervención}

Rastreo escalonado incluyendo glucemia al azar, hemoglobina glicosilada y glucemia en ayunas; prueba de tolerancia oral a la glucosa utilizado como prueba confirmatoria

\section{Medición de resultados principales}

Mortalidad por cualquier causa (resultado principal); mortalidad por cáncer, mortalidad por enfermedad cardiovascular, mortalidad por otras causas y muertes relacionadas a DBT2 (resultados secundarios). Se realizó análisis por intención de rastrear. El seguimiento mediano fue de 9,6 años.

\section{Resultados}

Se diagnosticó DBT2 en 466 casos (3\%).

Tabla 1: Mortalidad de distintas causas entre rastreados y no rastreados

\begin{tabular}{|c|c|c|c|c|c|c|c|}
\hline & \multicolumn{3}{|c|}{ Control } & \multicolumn{3}{|c|}{ Rastreo } & \multirow[b]{2}{*}{$\begin{array}{l}\text { Hazard ratio } \\
\text { (IC 95\%) }\end{array}$} \\
\hline & $\mathrm{N}^{\circ}$ muertes & $\begin{array}{l}\text { Personas-año de } \\
\text { seguimiento }\end{array}$ & $\begin{array}{l}\text { Tasa por } 1.000 \\
\text { personas/año } \\
\text { (IC 95\%) }\end{array}$ & $\mathrm{N}^{\circ}$ muertes & $\begin{array}{l}\text { Persona-año de } \\
\text { seguimiento }\end{array}$ & $\begin{array}{l}\text { Tasa por } 1.000 \\
\text { personas/año } \\
\text { (IC 95\%) }\end{array}$ & \\
\hline Mortalidad (todas las causas) & 377 & 38.126 & $\begin{array}{c}9,89 \\
(8,94 \text { a } 10,94)\end{array}$ & 1.532 & 145.930 & $\begin{array}{c}10,50 \\
(9,99 \text { a } 11,04)\end{array}$ & $\begin{array}{c}1,06 \\
(0,90 \mathrm{a} 1,25)\end{array}$ \\
\hline Mortalidad cardiovascular & 124 & 38.126 & $\begin{array}{c}3,25 \\
(2,73 \text { a } 3,88)\end{array}$ & 482 & 145.930 & $\begin{array}{c}3,30 \\
(3,02 \text { a } 3,61)\end{array}$ & $\begin{array}{c}1,02 \\
(0,75 \text { a } 1,38)\end{array}$ \\
\hline Mortalidad por cáncer & 169 & 38.126 & $\begin{array}{c}4,43 \\
(3,81 \text { a } 5,15)\end{array}$ & 697 & 145.930 & $\begin{array}{c}4,78 \\
(4,43 \text { a } 5,14)\end{array}$ & $\begin{array}{c}1,08 \\
(0,90 \text { a } 1,30)\end{array}$ \\
\hline Mortalidad por otras causas & 84 & 38.126 & $\begin{array}{c}2,20 \\
(1,78-2,73)\end{array}$ & 353 & 145.930 & $\begin{array}{c}2,42 \\
(2,18 \text { a } 2,68)\end{array}$ & $\begin{array}{c}1,10 \\
(0,87 \text { a } 1,39)\end{array}$ \\
\hline
\end{tabular}

\section{Conclusiones}

El rastreo de DBT2 en personas con riesgo aumentado de desarrollarla, no mostró disminuir la mortalidad por todas las causas, por causa cardiovascular, ni aquella relacionada a diabetes.
Fuentes de financiamiento: Wellcome Trust; UK Medical Research Council; National Health Service research and development support; UK National Institute for Health Research; University of Aarhus, Denmark; Bio-Rad.

\section{Comentario}

Si bien la detección temprana pudo haber sido beneficiosa para los individuos diagnosticados, la proporción de éstos pudo no haber sido lo suficientemente grande como para afectar la mortalidad global. Como fortalezas de este estudio cabe destacar que midió un resultado primario tan importante y objetivo como mortalidad, y el hecho de ser un estudio llevado a cabo en el ámbito de atención primaria. También presentó algunas limitaciones; los participantes tuvieron menor mortalidad que aquellos que no participaron (sesgo de voluntarios sanos); sólo se realizó una ronda de rastreo; los centros de salud participantes atendían una población mayoritariamente blanca y con mayor riqueza que el promedio; y el tiempo de seguimiento (10 años) puede haber sido insuficiente para encontrar diferencias en mortalidad en una población asintomática al inicio del estudio.
El rastreo de DBT2 a nivel poblacional podría ser más beneficioso si se realizara en pacientes de riesgo y se complementara con consejería sobre cambios en estilo de vida.

En 2012 la Fuerza de Tareas Canadiense sobre salud preventiva actualizó su guía rastreo de DBT2 en adultos. ${ }^{1}$ Basándose en una clasificación de riesgo de desarrollar diabetes en 10 años (según edad, obesidad, historial de glucemias elevadas, hipertensión arterial, antecedentes familiares de diabetes, sedentarismo y dieta); la guía recomienda no realizar rastreo en adultos con moderado o bajo riesgo, rastrear cada 3 a 5 años a adultos con alto riesgo, y anualmente en los de muy alto riesgo. Quedaría pendiente evaluar la factibilidad de implementar estas recomendaciones a nuestra práctica cotidiana.

Ma. Victoria Salgado [ Servicio de Medicina Familiar y Comunitaria del Hospital Italiano de Buenos Aires. maria.salgado@ @iba.org.ar ]

Salgado MV. El rastreo de Diabetes Tipo 2 en adultos de alto riesgo no disminuiría la mortalidad. Evid Act Práct Ambul; Abr-Jun 2013; 16(2):45. Comentado de: Simmons RK, Echouffo-cheugui JB, Sharp SJ, et al. Screening for type 2 diabetes and population mortality over 10 years (ADDITION-Cambridge): a cluster-randomised controlled trial. Lancet. 2012 Nov 17;380(9855):1741-8. PMID: 23040422.

\section{Referencias}

1. Canadian Task Force on Preventive Health Care. Recommendations on Screening for Type 2 Diabetes in adults. CMAJ 2012;184(15):1687-96. Disponible en: http://www.cmaj.ca/content/184/15/1687.full.pdf+html. 